\title{
Investigate the Ozone Thickness and Temperature above Iraq during Severe and Strong Geomagnetic Storms
}

\author{
Najat M. R. Al-Ubaidi, T. I. Zahra \\ Department of Astronomy \& Space, College of Science, University of Baghdad, Baghdad, Iraq \\ Email: najatmr10@yahoo.com
}

How to cite this paper: Al-Ubaidi, N.M.R. and Zahra, T.I. (2018) Investigate the Ozone Thickness and Temperature above Iraq during Severe and Strong Geomagnetic Storms. Journal of Geoscience and Environment Protection, 6, 50-61. https://doi.org/10.4236/gep.2018.62004

Received: January 12, 2018

Accepted: February 24, 2018

Published: February 27, 2018

Copyright $\odot 2018$ by authors and Scientific Research Publishing Inc. This work is licensed under the Creative Commons Attribution International License (CC BY 4.0).

http://creativecommons.org/licenses/by/4.0/

\begin{abstract}
The aim of this research is to find the effect of the geomagnetic storms on the variation of the Ozone layer thickness by studying the hourly variations, daily average and monthly average of the Ozone amount above $\operatorname{Iraq}\left(38^{\circ} \mathrm{N}-49^{\circ} \mathrm{N}\right.$; $28^{\circ} \mathrm{E}-38^{\circ} \mathrm{E}$ ), and rates of productions correlated with fluctuations in geomagnetic field intensity. Data of total column ozone (tco3) and temperature $(\mathrm{t} 2 \mathrm{~m})$ were selected from the ERA satellite for year 2015, in which there are seven days strong and severe geomagnetic storms occurring along four months. From the monthly average in which the storm occurred, the contour maps for (tco3) and $(\mathrm{t} 2 \mathrm{~m})$ reveal that the thickness of Ozone layer in North of Iraq wider than the middle and South of Iraq for all stormy months except in October of 2015 appears which is the maximum in middle of Iraq. The temperature is reversely proportional with Ozone thickness. Results of the daily average appear that there are enhancements in (tco3) during the stormy day for the three Iraqi cities Muthanna, Baghdad, and Sulaymaniyah; the maximum values in winter and spring reach 356 DU in March. From the hourly variations of tco3 and $\mathrm{t} 2 \mathrm{~m}$ for three Iraqi cities, it is seen that in some events it decreases and others increase, not dependent on storm type. The slope of trend line for variation of (tco3) with the variation of $(\mathrm{t} 2 \mathrm{~m})$ drawn gives that there is no relationship between them along the three cities taken and for all 7 events. Finally from the percentage variation of $(\mathrm{tco} 3)$ and $(\mathrm{t} 2 \mathrm{~m})$ for two days before the storm and seven days after the storms it is indicated that there is a considerable unsystematic increase and decrease for the three cities chosen.
\end{abstract}

\section{Keywords}

Geomagnetic Storm, Total Column Ozone, Temperature 


\section{Introduction}

There are many indications about the relationship between geomagnetic activity and atmospheric ozone which is evidenced by a number of authors (e.g. Entzian and Grasnic, 1981; Jackman et al., 1990; Lastovicka et al., 1992; Hood, 1997). But there is still some uncertainty whether there are direct effects from solar activity or there are indirect processes. It was confirmed by Labitzke in 1997 that the association between the Sun and the ozone is not direct. Mlch and Lastovicka in (1995) revealed that $50 \%$ of the effect of geomagnetic storm depends principally on solar cycle and quasi-biennial oscillation (QBO) [1]. Lastovicka (1996) found that geomagnetic storm effects at the height of about $0-100 \mathrm{~km}$ are briefly reviewed in mid-latitudes (Europe). In the lower stratosphere and troposphere, there are some correlations with geomagnetic storms, but these effects are different, and they do not understand their mechanisms [2]. Lastovicka and Mlch (1999) found that the significant effects of geomagnetic storms on total ozone have been observed only in winter and for strong storms [3]. Belinskaya et al. (2001) demonstrated the latitudinal and longitudinal variations of the possible response of TOC to the solar and geomagnetic activity. The influence of the strong geomagnetic storms depends on the solar cycle phases, QBO-phases and longitude. The source of the TOC wave-like structure inter annual changes remains unclear; one possibility is that the transmission-reflection of upward propagated planetary scale waves is modified by the effects of solar UV changes in the upper stratosphere [4]. Yordan Tassev et al. (2003) studied the effect of solar Cosmic rays (CR) and the geomagnetic storm on the ozone profiles in the middle atmosphere and the regeneration of the ozone density in the lower stratosphere during night-time [5]. Lastovicka and Kriman Peter (2005) found that the main results of the investigations of the effects of geomagnetic storms' decrease on the total ozone may be due to sufficiently strong and statistically significant effects of geomagnetic storms and the Forbush decrease of the galactic cosmic ray flux appears to occur in the total ozone at the northern higher middle latitudes only for strong events in winter. The effect appears to be basically re-distribution of ozone [6]. Pancheva et al. (2007) studied the regional responses of the high-latitude of the mesosphere-lower thermosphere (MLT) winds to the very strong geomagnetic storms that occurred on 29 and 30 October 2003. It was found that the response of the MLT dynamics to the first geomagnetic storm occurring in the daytime and accompanied by solar proton fluxes is very different from those to the second and third geomagnetic storms with onsets during the night time [7]. Damiani et al. (2009) investigated the effects of solar energetic particles (SEPs) on the polar atmosphere in three different seasons, and they found that the even events with limited particle flux in the range of 15 $40 \mathrm{MeV}$ are able to change the abundance of the minor constituents in the mesosphere and upper stratosphere [8]. Cooper et al. (2010) showed a strong increase in spring time ozone mixing ratios during 1995-2008 [9]. In (2012) Saa- 
diyah analyzed the spatial-temporal structure of the daily total Ozone column (TOC) during years (2004-2011), over various cities in Iraq, which indicated that the daily variation of TOC in Southern part of Iraq lower than the central and Northern parts of Iraq, but the seasonal variation showed that there is a higher diurnal TOC variations in Spring and Summer months than Autumn and Winter months [10]. Tzung-May Fu et al. (2015) showed that the enhanced biogenic emissions and the accelerated photochemical reaction rates associated with warmer temperatures both act to increase surface ozone [11]. Marta Zossi de Artigas et al. (2016) studied the effects of energetic particles precipitation on stratospheric ozone in the Southern Hemisphere statistically significant variation in total ozone content at middle latitudes of the Southern Hemisphere is observed. The variations depend on the intensity of geomagnetic disturbances and the geomagnetic longitude [12]. The aim of this study is to find the effect of geomagnetic storms on the total column ozone (tco3) and temperature over Iraqi region during year 2015 .

\section{Data Selection}

In this research, the year 2015 was chosen on the basis that it was the year in which the most geomagnetic storms occurred throughout this year, so we were able to take four storms that occurred in the four seasons, spring (March), the summer (June), autumn (October) and winter (December), which helped us to take a comprehensive study of the impact of storms with Seasons and Latitude. In this research the data for total column ozone (tco3) and temperature ( $\mathrm{t} 2 \mathrm{~m})$ at height $(2 \mathrm{~m})$ above the surface of the Earth were selected for Iraqi region $\left(38^{\circ} \mathrm{N}-\right.$ $49^{\circ} \mathrm{N} ; 28^{\circ} \mathrm{E}-38^{\circ} \mathrm{E}$ ) from the site (http://apps.ecmwf.int/datasets). The year 2015 are taken in which seven severe and strong geomagnetic storms occurred during four months shown in Table 1.

\section{Data Analysis}

From data selected above Iraqi region for the year 2015, there is only four months (March, June October and December) in which the storms occurred. Figure 1 reveals the hourly (Dst-index), the Dst value is used to define the type and the strength of a geomagnetic storm [13], it found that there is five strong

Table 1. Geomagnetic storms during year 2015.

\begin{tabular}{ccccccc}
\hline Event no. & Day & Month & Year & Hour Begin & Hour End & Type \\
\hline 1 & 17 & 3 & 2015 & 16 & 24 & Severe \\
2 & 18 & 3 & 2015 & 1 & 11 & Strong \\
3 & 22 & 6 & 2015 & 21 & 22 & Strong \\
4 & 23 & 6 & 2015 & 1 & 18 & Severe \\
5 & 7 & 10 & 2015 & 20 & 24 & Strong \\
6 & 20 & 12 & 2015 & 18 & 24 & Strong \\
7 & 21 & 12 & 2015 & 1 & 11 & Strong \\
\hline
\end{tabular}


Dst with UT (3/2015)



Dst with UT (10/2015)



Hour of month
Dst with UT (6/2015)


Figure 1. Dst (nT) values of geomagnetic storm during four months from year 2015.

storms $(-200 \mathrm{nT}<$ Dst $<-100 \mathrm{nT})$ and two severe storms $(-350 \mathrm{nT}<\mathrm{Dst}<-200$ $\mathrm{nT})$ in year 2015 .

Drawing contour maps for the monthly average Figure 2(a) for (tco3) in Dobson Unite (DU) and Figure 2(b) for (t2m) in (K), also contour maps daily average of (tco3) and (t2m) which are represented in Figures $3(\mathrm{a})-(\mathrm{c})$ and Figures 4(a)-(c) for four events selected, two severe and two strong from the seven events in 2015. These four events are occurred in (17 March, 23 June, 6 October and 20 December 2015) respectively, where a) two days before the geomagnetic storm, b) for the stormy day, and c) seven days after the geomagnetic storm.

To reveals the changes of tco 3 and $\mathrm{t} 2 \mathrm{~m}$ during the geomagnetic storms, to illustrate this more easily, Iraqi region divided into three categories South represented by Muthanna (latitude, $30^{\circ} \mathrm{N}$; longitude, $45^{\circ} \mathrm{E}$ ), Middle Baghdad (latitude, $33^{\circ} \mathrm{N}$; longitude, $44^{\circ} \mathrm{E}$ ), and North Sulaymaniyah (latitude, $35^{\circ} \mathrm{N}$; longitude, $45^{\circ} \mathrm{E}$ ). As above only four events selected for this study which is represented in Figure 5, shows the daily variation (represented by only eight hours $0,3,6,9,12,15,18$, and 21 in universal time) through the day of tco3 and the $\mathrm{t} 2 \mathrm{~m}$ to the four events chosen, for three days two days before storm, day of geomagnetic storm and Seven days after the geomagnetic storm.

To find the relationship between the thickness of Ozone layer (tco3) and temperature change $(\mathrm{t} 2 \mathrm{~m})$ during the geomagnetic storm, data taken from the same location and for eight hours during the stormy day. Figure 6 reveals the hourly variation of (tco3) with respect to hourly variation of ( $t 2 \mathrm{~m})$ for four events occurred from year 2015 for three Iraqi cities chosen in this research. The curve fitting of this drawing gives the trend line equation in which the slopes are represented in Table 2 . 




(a)


(b) Temperature 6 - 2015


Figure 2. Monthly average contour maps, (a) total column Ozone (tco3) and (b) temperature (t2m). 







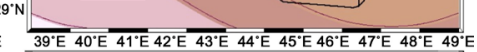



Total column ozone (21-6-2015)

Total column ozone (23-6-2015)


Total column ozone (30-6-2015)



T)



39.


Total column ozone (14-10-2015)


39.

Figure 3. Daily average contour maps of the tco3, (a) two days before the geomagnetic storm, (b) day of the geomagnetic storm, (c) seven days after the geomagnetic storm. 



(b)


Figure 4. Daily average contour maps of the $\mathrm{t} 2 \mathrm{~m}$, (a) two days before the geomagnetic storm, (b) day of the geomagnetic storm, (c) seven days after the geomagnetic storm. 



Figure 5. Daily variation of the tco3 and the t $2 \mathrm{~m}$ for three days two days before storm, day of geomagnetic storm and Seven days after the geomagnetic storm. For four events occurred from year 2015 and for three Iraqi cities. 
$17 / 3 / 2015$


\section{$23 / 6 / 2015$}


\section{$7 / 10 / 2015$}



$20 / 12 / 2015$


Figure 6. Hourly variation of (tco3) with respect to hourly variation of (t2m) for four events occurred from year 2015 and for three Iraqi cities. 
Table 2. Variation of total column ozone with temperature for three Iraqi cities, $\mathrm{Mu}$ thanna, Bagdad, Sulaymaniyah during the day of geomagnetic storm.

\begin{tabular}{ccccc}
\hline \multicolumn{5}{c}{ Slope } \\
\hline & \multicolumn{1}{c}{ Event } & Muthanna & Baghdad & Sulaymaniyah \\
\hline 1 & $17 / 3 / 2015$ & -0.1123 & -0.2827 & 0.3584 \\
3 & $23 / 6 / 2015$ & 0.2189 & 0.159 & -0.013 \\
5 & $7 / 10 / 2015$ & -0.0566 & 0.1725 & 0.4872 \\
6 & $20 / 12 / 2015$ & -0.3817 & -0.4876 & 0.166 \\
\hline
\end{tabular}

\section{Results and Discussion}

From results above for the monthly average contour maps of (tco3) and $(\mathrm{t} 2 \mathrm{~m})$ it reveals that, in general the thickness of Ozone layer in spring and winter are greater than summer and autumn. Also in the North of Iraq wider than the Middle and South of Iraq for all seasons except in autumn (month 10 from year 2015), there is anomaly in which the thickness of Ozone is wider in the west and Middle of Iraq than the other countries. About the temperature in the Middle and South of Iraq greater than the North and for all stormy months and there is an inverse relation between ( $t c 03)$ and $(\mathrm{t} 2 \mathrm{~m})$.

From the daily average of tco3 for the two days before the storm, stormy day, and seven days after the storm, it is seen that for spring, autumn and winter for over the three cities chosen the tco3 seems approximately increases during the stormy days except in summer it is decreases for all cities. The maximum values of tco3 in Spring and Winter utmost in March it reaches 356 DU. About the temperature in North of Iraq lower than Middle and South, seems approximately increases during the stormy days in spring, autumn and winter, also it is decreases in summer. The maximum value of $\mathrm{t} 2 \mathrm{~m}$ reaches $303 \mathrm{~K}$ in June.

For more comprehensive study, eight hours from the day taking for two days before the storm, stormy day and seven days after, to see the impact of storms on total column Ozone and temperature with Seasons and Latitude. From comparing between the stormy day and two days before the results shown that during the geomagnetic storms the tco3 decreases for all seasons and latitudes chosen with respect to two days before the stormy day, except in summer it is increases and in south (Muthana) it increases in spring and decreases in summer. Also for the temperature it is increases for all seasons and latitudes except in summer it is decreases. To compare between the tco3 in stormy hours and after seven days, it seen that the tco3 decreases for all seasons and latitudes except in summer it is increases for all latitudes chosen and in north of Iraq. About the $\mathrm{t} 2 \mathrm{~m}$ it is increases in spring and winter except in north it is decreases in winter; also it is decreases in summer and autumn.

To find if there is any relationship between the tco3 and $\mathrm{t} 2 \mathrm{~m}$, which gives the climate change during the geomagnetic storms for year 2015, Figure 6 and Table 2 reveals that, there is a fluctuation between direct and inverse relation in all 
seasons and latitudes. There is no clear relationship that can be deduced in this study, which requires consideration of other factors that have an effect on changes in temperature which are not included in this study.

\section{Conclusion}

From the result and discussion above, it appears that, the thickness of Ozone layer in spring and winter is greater than that of summer and autumn. Also in the North of Iraq wider than the Middle and South of Iraq for all seasons except in autumn (month 10 from year 2015), there is anomaly in which the thickness of Ozone is wider in the West and Middle of Iraq than the other countries. About the temperature in the Middle and South of Iraq greater than the North and for all stormy months, there is an inverse relation between ( $\mathrm{tco} 3)$ and ( $\mathrm{t} 2 \mathrm{~m})$. For the seasonal and latitude variation between $\mathrm{tco} 3$ and $\mathrm{t} 2 \mathrm{~m}$ by taking the relative comparisons between days before and after with stormy day, it seems that there is an inverse relation between tco 3 and $t 2 \mathrm{~m}$ for all seasons and latitudes taken in this research, but there is a fluctuation between direct and inverse relation between tco 3 and $\mathrm{t} 2 \mathrm{~m}$ for the stormy day in all seasons and latitudes. There is no clear relationship that can be deduced in this study.

\section{Acknowledgements}

This work relates to University of Baghdad/College of Science/Department of Astronomy and Space. The data are provided from the European Centre for Medium-Range Weather Forecasts (ECMWF) and WDC, for whom I would like to introduce my utmost appreciation and thanks.

\section{References}

[1] Kazimirovsky, E.S., Belinskaya, A.Yu., Matafonov, G.K., Zherebtsov, G.A. and Pirog, A.M. (1999) The Possible Response of the Total Ozone Content on the Solar and Geomagnetic Activity. Advances in Space Research, 24, 661-664. https://doi.org/10.1016/S0273-1177(99)00474-3

[2] Lastovicka J. (1996) Effects of Geomagnetic Storms in the Lower Ionosphere, Middle Atmosphere and Troposphere. Journal of Atmospheric and Terrestrial Physics, 58, 831-843. https://doi.org/10.1016/0021-9169(95)00106-9

[3] Lastovicka J. and Mlch, P. (1999) Is Ozone Affected by Geomagnetic Storms? Advances in Space Research, 24, 631-640. https://doi.org/10.1016/S0273-1177(99)80136-7

[4] Belinskaya A., Kazimirovsky, Ed., Matafonov, G. and Sych, R. (2001) the Regional Peculiarities of the Total Ozone Content Variations Caused by Solar Geomagnetic Phenomena. Advances in Space Research, 27, 2007-2011. https://doi.org/10.1016/S0273-1177(01)00306-4

[5] Yordan, T., Peter, I.Y., Velinov, I., Mateev, L. and Tomova, D. (2003) A Comparison between Effects of Solar Proton Events and of Geomagnetic on the Ozone Profiles. Advances in Space Research, 31, 2163-2168. https://doi.org/10.1016/S0273-1177(03)00126-1

[6] Jan, L. and Krizan, P. (2005) Geomagnetic Storms, Forbush Decreases of Cosmic 
Rays and Total Ozone at Northern Higher Middle Latitudes. Journal of Atmospheric and Solar Terrestrial Physics, 67, 119-124.

https://doi.org/10.1016/j.jastp.2004.07.021

[7] Pancheva, D., Singer, W. and Mukhtarov, P. (2007) Regional Response of the Mesosphere-Lower Thermosphere Dynamics over Scandinavia to Solar Proton Events and Geomagnetic Storms in Late October 2003. Journal of Atmospheric and Solar-Terrestrial Physics, 67, 1075-1094. https://doi.org/10.1016/j.jastp.2007.04.005

[8] Damiani, A., Diego, P., Laurenza, M., Storini, M. and Rafanelli, C. (2009) Ozone Variability Related to Several SEP Events Occurring during Solar Cycle No. 23. Advances in Space Research, 43, 28-40. https://doi.org/10.1016/j.asr.2008.06.006

[9] Cooper, O.R., Parrish, D.D., Stohl, A., Trainer, M., Ne'de'lec, P., Thouret, V., Cammas, J.P., Oltmans, S.J., Johnson, B.J., Tarasick, D., Leblanc, T., McDermid, I.S., Jaffe, D., Gao, R., Stith, J., Ryerson, T., Aikin, K., Campos, T., Weinheimer, A. and Avery, M.A. (2010) Increasing Springtime Ozone Mixing Ratios in the Free Troposphere over Western North America. Nature, 463, 344-348. https://doi.org/10.1038/nature08708

[10] Saadiyah, H.H. (2012) Temporal and Spatial Variabilities of Total Ozone Column over Iraq. Asian Transactions on Science \& Technology, 2, 11-17.

[11] Fu, T.-M., Zheng, Y., Paulot, F., Mao, J. and YantoSca, R.M. (2015) Positive but Variable Sensitivity of August Surface Ozone to Large-Scale Warming in the Southeast United States. Nature Climate Change, 5, 454-458. https://doi.org/10.1038/nclimate2567

[12] de Artigas, M.Z., Zotto, E.M., Mansilla, G.A. and de Campra, P.F. (2016) Effects of Energetic Particles Precipitation on Stratospheric Ozone in the Southern Hemisphere. Advances in Space Research, 58, 2080-2089. https://doi.org/10.1016/j.asr.2016.02.019

[13] Roy, I., Asikainen, T., Maliniemi, V. and Mursula, K. (2016) Comparing the Influence of Sunspot Activity and Geomagnetic Activity on Winter Surface Climate. Journal of Atmospheric and Solar-Terrestrial Physics, 149, 167-179. https://doi.org/10.1016/j.jastp.2016.04.009 